\title{
The curriculum question in higher education
}

\author{
Kate O'Connor \\ University of Melbourne, VIC, Australia
}

koconnor@unimelb.edu.au

One problem facing Australian curriculum inquiry is the visibility of curriculum as a subject of scholarly debate. This is particularly so for higher education where, as in the UK, the focus of debate is on student learning and engagement, and curriculum has tended to be a "missing term' (Barnett and Coate 2005, p. 1) in policy as well as scholarship. What problems does this raise for how university education is understood and administered? And what challenges and opportunities exist for curriculum research within this context? In this paper, I engage with these questions, drawing on findings from research which examined new online initiatives being developed at two Australian universities.

\section{Curriculum and the 'learnification' of higher education}

Curriculum and curriculum inquiry are ambiguous terms, meaning different things at different times, in different places and to different people. Despite this, both are traditionally concerned with the 'what' of education, in ways which foreground knowledge as a critical issue (Green 2018). Within higher education, there is currently significant debate about what university teaching should look like, what it should emphasise and how it can be better structured to meet the needs of more diverse student populations. Yet, while these arguments attend to some elements of curriculum, the role of formal knowledge in education tends to be neglected and questions around what is taught and why are primarily positioned outside the frame of debate.

The literature on university teaching is widespread and over the last few decades books and papers on how to teach in higher education have proliferated. These works emphasise the importance of creating 'learning experiences' that engage students and focus on their own constructions of knowledge, and on building coherent programs that build towards and 'align' with predefined outcomes. In one influential publication, Barr and Tagg (1995) for example, argue for a shift from what they call an instruction paradigm, where knowledge is seen as being transferred from teachers to students and the focus is on covering content, to a learning paradigm, where the role of the teacher is to facilitate students in constructing their own knowledge and the focus is on student learning and understanding. They argue that under a learning paradigm, the choice of 'means' (activities, lectures etc.) is not fixed but the 'ends' (outcomes) are, "allowing the means to vary in its constant search for the most effective and efficient paths to student learning” (Barr and Tagg, 1995, 10).

Within these and similar arguments (see e.g. Biggs and Tang 2011, Brown and Adler 2008), curriculum, in terms of 'what' is taught, is typically taken for granted, and seen as unproblematically able to be transferred into a new form, with the transformative effect of incorporating 'active learning' approaches or reconfiguring courses around learning outcomes about clarifying or refining what was truly important within a given course, rather than potentially changing that. Instead, it is argued that the question of 'what' knowledge is included matters less than the question of how students engage with knowledge. The focus, as Brown and Adler (2008, p. 18) write "is not so much on what we are learning but how we are learning". These trends are part of what Biesta $(2009$, p. 39) has called the "learnification" of education. He argues that this 'language of learning' constructs education 
as a 'process' in ways which are "open - if not empty with regard to content and direction" (p. 9) or purpose.

\section{Foregrounding curriculum in higher education}

In this context, I conducted a research project which was explicitly designed to consider new online initiatives in higher education from a curriculum perspective, meaning in this case an attention to what was being emphasised and enacted in relation to knowledge within the new reforms. I looked at four new initiatives located at two institutions, drawing on interviews with the institutional leaders and lecturers involved along with analyses of policy documentation and curriculum materials. These new initiatives were different, but all had in common a model whereby the subject content was developed by lecturers within universities but delivered via platforms external to the university, with predominantly very little lecturer involvement in the delivery of the subject. Such approaches have been described as an 'unbundling' of the instructional (curriculum development) role from the delivery (teaching) activities (see Neely and Tucker 2010), and are becoming more popular in the design of online reforms. The research focused on the intentions, practices and assumptions of the people involved, and the emphases and tensions evident in how they grapple with questions of knowledge and its teaching. This focus drew attention to some issues and concerns not widely acknowledged within higher education debates, and in doing so highlighted the issue of sidelining curriculum as a matter of concern.

At both the institutions I looked at, the online initiatives were positioned as a salve to poor teaching, and a means of encouraging constructivist and active learning pedagogies as well as outcomes-based approaches to education. The institutional leaders I spoke with made it clear that they wanted lecturers to focus on the process of students' knowledge development, to reduce the amount of content taught to allow time for students to engage with concepts in active and constructivist ways. They critiqued 'transmission model' approaches and commented on 'the never-ending problem of asking lecturers to curtail content'. And they commented that 'the process of [curriculum] development needs to be changed' to 'start with the end in mind'. Here, the institutional leaders promoted a mainstreamed, common approach to teaching, informed by generalised ideas about what interests and engages students (doing things, interacting with each other) and what students are capable of. They saw such approaches as beneficial for all subjects and forms of knowledge, regardless of their distinctive purposes, orientations or underlying knowledge structures (Muller 2009). One institutional leader for example commented 'the more there is centralised control and less opportunity for an individual academic to go off somewhere, the better it is for our students'.

The institutional leaders I spoke with were clearly influenced by key arguments about what good teaching looks like, but their understandings of what that requires were limited and they tended to not focus on the kinds of conditions necessary for the forms of teaching and learning they want to occur. They sought to encourage constructivist forms of teaching, but did not acknowledge the challenge of doing so within online reforms which allowed for very little interaction between lecturers and students. They assumed that lecturers can do what they want in respect of the knowledge to be conveyed, regardless of other directions relating to curriculum design and pedagogy. And they took for granted that the content and purpose of curriculum was unchallenged by the new online forms and that the substance of curriculum required little change between iterations and cohorts of students.

Here, the institutional leaders' aims for the new online initiatives highlight some particular problems with the ways in which curriculum is being understood within higher education 
institutions and within wider debates about university teaching. They ignore the importance of specificity and context and the different ways in which the purposes and practices of those in different disciplines and professional fields might be differentially affected by new ways of constructing curriculum and education (Muller 2009, Yates et al. 2017). They neglect the complex relations between what is taught and how that is approached in what students receive as knowledge within an education (Bernstein 1975). And they reflect an inattention to knowledge as a critical issue for teaching and to curriculum as a contested site of struggle over the question of what counts as knowledge, rather than a simple process deriving from agreed outcomes (Karseth 2006). The lecturers at these institutions were asked to work with new platforms and new contexts, but there was little acknowledgement at the institutional level of the difficult and complex work this involves or the potential for conflict between different kinds of agendas.

The inattention to these issues raised some particular problems for the lecturers developing new subjects for the online reforms. In contrast to the assumptions of the institutional leaders, the particular pedagogies inscribed within the online initiatives and the ways these were taken up by the lecturers were not neutral in terms of the knowledge conveyed, but gave rise to different possibilities. In their practices of curriculum construction for the new platforms, the lecturers became concerned with refining and reworking their predefined content material, with rigid assessment expectations and parameters, and in many cases with over-prescribing and directing student activities. In the vast majority of cases, with limited opportunities for interacting with students, the lecturers were not able to develop their curriculum content in ways which referenced where students were coming from, and they were not able to teach that content in a way which allowed them to engage with students' own understandings and concepts in a meaningful way. The lecturers were also impacted differently by the new arrangements, with those located in 'pure' disciplinary fields such as biology and classical studies seeing the requirements for content reduction as more challenging to their purposes than those located in professional fields.

\section{Curriculum inquiry and the problem of visibility}

These issues point to the importance of making curriculum an explicit object of inquiry, and the problems raised where the complexities involved in curriculum making are neglected. As highlighted, the inattention to curriculum as an explicit focus of higher education policy and scholarly debate has created significant silences and blind-spots in institutional and academic thinking, and as a result problems in the ways in which new reforms and policies are conceptualised and instigated.

This inattention to curriculum also draws attention to the problem of visibility of curriculum inquiry in higher education policy and research. The current higher education context, in which issues of student learning and outcomes take precedence, effectively silence curriculum questions about purpose and content and the what and why of education (Biesta 2009). Curriculum inquiry is necessarily "informed by government policies and procedures" and "responsive to national situations" (IAACS 2017). For higher education, the lack of attention to curriculum issues at the policy level means that curriculum inquiry brings a valuable and different perspective to current debates, but it also makes it more difficult to position research within those debates and to speak back against dominant perspectives.

Related issues of visibility are also evident within curriculum inquiry in Australia more broadly. Although the development of the Australian Curriculum did bring renewed attention to curriculum at the school level, concerns related to learning and pedagogy on the one hand, 
and testing and effectiveness on the other, continue to take precedence. Academics with the most significant influence on school curriculum policy and practice are more likely to come from outside the field of curriculum inquiry, with interests in fields such as educational assessment and measurement. Additionally, even within the wider educational research field, curriculum inquiry lacks visibility. Within the Australian Association for Research in Education, there is no special interest group (SIG) dedicated to curriculum inquiry, but work in that field is spread across multiple SIGs, including those focused on policy and politics and history and education. And those who do engage with curriculum inquiry also identify their work in range of ways, often not positioning curriculum inquiry as their primary academic identity.

These issues are further exacerbated by the amorphous nature of the field, and the difficulties this presents for defining what work locates within it. Research locating within curriculum inquiry is not tied to exploring given questions in a particular way and the concerns which mark its research are not exclusive to that field but also evident in other areas of educational research. In earlier work I conducted with Lyn Yates (O'Connor and Yates 2010), we attempted to review and categorise postgraduate scholarship within curriculum inquiry in Australia but struggled with the question of what constitutes a curriculum thesis, particularly in relation to studies of teaching and learning. In these cases, we chose to include theses that indicated some interest in the issue of what is conveyed to students, and to exclude those that focused primarily on the effectiveness of particular pedagogies or characteristics of particular students. Such decisions are unlikely to accord with everyone's perspectives of what curriculum inquiry constitutes and the process we took highlights the conceptual and practical difficulty of developing even a rough overview of what curriculum research might entail.

However, although the boundaries of curriculum inquiry are fuzzy and there is significant overlap with other areas of educational research, taking curriculum as an explicit object of inquiry brings different issues into focus that are less evident where others are made precedent. Curriculum inquiry encompasses a range of different perspectives and approaches, each of which offers potentially valuable insights for understanding and engaging with the current educational context. Curriculum practices are changing in higher education as well as schooling, and there is an urgent need to critique and address the issues arising from new curriculum constructions. Work in curriculum inquiry has much to offer in this regard, but is challenged in Australia by the sidelining of curriculum as an issue of importance, and the relative (in)visibility of the curriculum inquiry field.

\section{References}

Barnett, R., \& Coates, K. (2005). Engaging the curriculum in higher education. Maidenhead, Berkshire: Open University Press.

Barr, R. B., \& Tagg, J. (1995). From teaching to learning - A new paradigm for undergraduate education. Change, November/December, 13-24.

Bernstein, B. (1971). Class, Codes and Control (Vol. 1). London and Boston: Routledge and Kegan Paul.

Biesta, G. (2009). Good education in an age of measurement: On the need to reconnect with the question of purpose in education. Educational Assessment, Evaluation and Accountability, 21(1), 33-46.

Biggs, J. B., \& Tang, C. (2011). Teaching for quality learning at university: What the student does. $4^{\text {th }}$ Ed. Open Maidenhead, Berkshire: Open University Press. 
Seely Brown, J. \& Adler, R. (2008). 'Minds on Fire: Open Education, the Long Tail, and Learning 2.0. Educause Review, 43(1), 17-22.

Green, B. (2018). Engaging curriculum: Bridging the curriculum theory and English education divide. New York \& London: Routledge.

IAACS (International Association for the Advancement of Curriculum Studies) (2017). About IAACS. Retrieved from http://www.iaacs.ca/about/

Karseth, B. (2006). Curriculum restructuring in higher education after the Bologna Process: A new pedagogic regime? Revista española de educación comparada 12, 255-284.

Muller, J. (2009). Forms of knowledge and curriculum coherence. Journal of Education \& Work, 22(3), 205-226.

Neely, P., \& Tucker, J. (2010). Unbundling faculty roles in online distance education programs. The International Review of Research in Open and Distance Learning, 11(2), 20-32.

Yates, L. \& O'Connor, K. (2010). Classifying curriculum scholarship in Australia: A review of postgraduate theses 1975-2005. Australian Educational Researcher, 37(1), 125-143.

Yates, L., Woelert, P., Millar, V., \& O'Connor, K. (2017). Knowledge at the crossroads: Physics and history in the changing world of schools and universities. Singapore: Springer. 


\section{University Library}

\section{- M M I E R R V A gateway to Melbourne's research publications}

Minerva Access is the Institutional Repository of The University of Melbourne

Author/s:

O'Connor, K

Title:

The curriculum question in higher education

Date:

2018-04-01

Citation:

O'Connor, K. (2018). The curriculum question in higher education. Curriculum Perspectives, 38 (1), pp.73-76. https://doi.org/10.1007/s41297-017-0036-4.

Persistent Link:

http://hdl.handle.net/11343/282647 